Clinical Vistas

\section{Nosocomial myiasis in a Canadian intensive care unit}

A 65-year-old woman presented to the emergency department with respiratory distress, congestive heart failure and atrial fibrillation thought to be secondary to pneumonia and myocardial infarction. Intubation was performed, and she was admitted to the intensive care unit. A nasogastric feeding tube was placed and appropriate therapy initiated. The patient had numerous comorbities, including endstage renal disease, diabetes mellitus, stroke, myocardial infarction, peripheral vascular disease, hypertension and emphysema, and she was receiving hemodialysis. An examination of her head performed on admission did not reveal any abnormalities.

Three days later, numerous maggots (6-7 $\mathrm{mm}$ long) were observed in the patient's nasal cavities (Figure I) and at the left medial canthus (Figure 2). During this period, an adult fly (a green blow fly or a green bottle fly) was seen in the intensive care unit. The patient was in a windowless private room that had an open door. The intensive care unit had no windows to the outdoors; thus, it was assumed that the fly had entered the intensive care unit from another part of the hospital.

A magnetic resonance imaging scan of the head revealed slight thickening of the nasal mucosa. An ophthalmologist manually removed about 20 larvae from the canthus. None of the larvae had invaded the lacrimal duct. Using saline, an otolaryngologist irrigated about roo larvae from the nasopharynx. There was no evidence of deeper tissue penetration. Cefotaxime was administered for 5 days as prophylaxis against bacterial complications. The patient recovered fully and was later discharged.

The larvae that were removed from the patient's canthus and nasopharynx were identified by 2 of us (B.S. and B.G.) as second instar Lucilia illustris (green blow fly) of the family Calliphoridae. Lucilia species are primarily scavengers of vertebrate carrion (e.g., exposed meat and fish), and several species are important agents of myiasis in livestock and humans. Facultative myiasis occurs when flies lay their eggs in decaying tissue or in malodorous open wounds or orifices, including the nasopharynx and eye structures, as occurred in our patient.

Female blow flies can lay up to several hundred eggs in a mass. The eggs and larvae usually develop on ephemeral substrates, and they have evolved rapid life cycles, the speed of which is dependent on temperature.

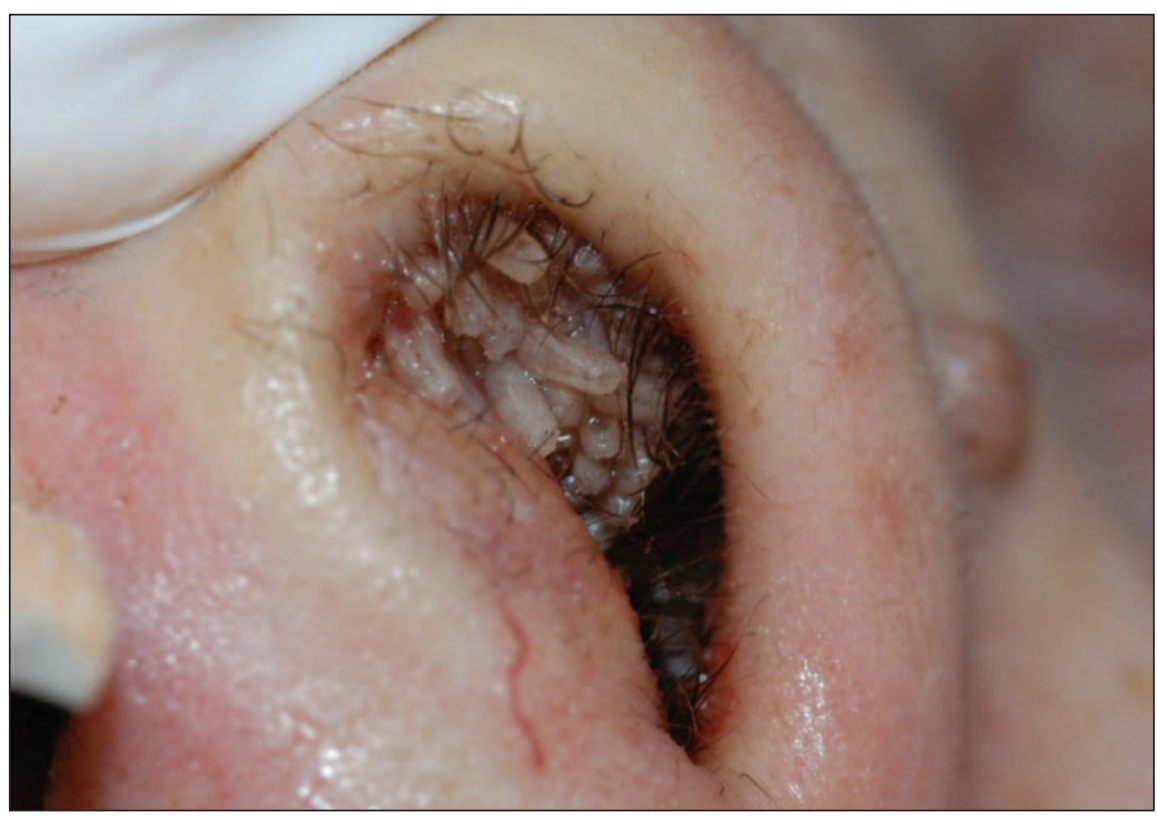

Figure 1: Larvae in the left anterior naris (viewed inferiorly).

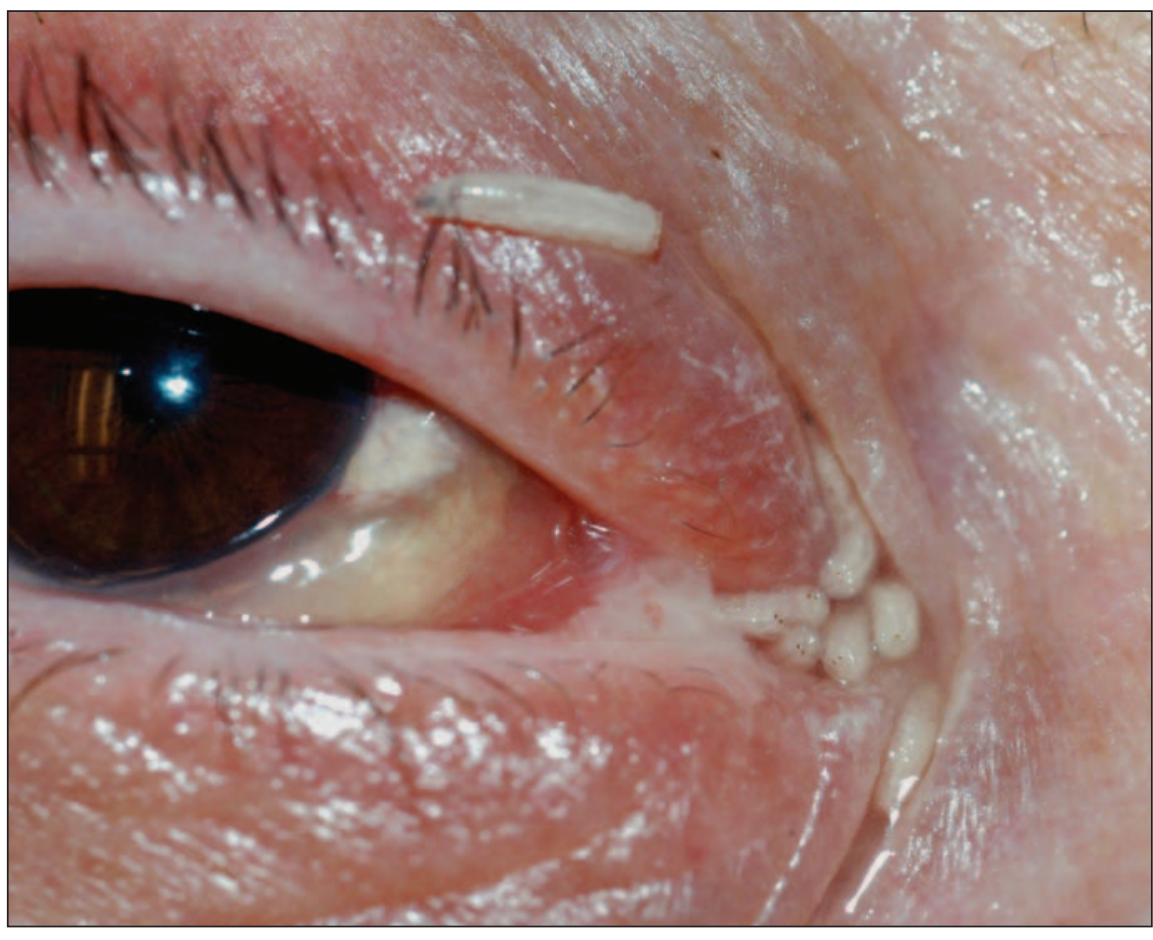

Figure 2: Larvae visible after manual opening of the eye. 
The larvae molt 3 times, and after feeding for I-Io days, they pupate in the surrounding media. Based on the incubation and development times of a related species, ${ }^{1}$ second instar larvae should take 2 days to develop; thus, in our patient's case the infestation was nosocomially acquired.

Nosocomial myiasis is rare. Predisposing risk factors include debilitation, blood or odors of decomposition, inattention to proper nursing care and summer season. Altered consciousness or hypoesthesia may prevent detection of a fly, and paralysis may prevent the patient from fending it off. Finally, comorbidities that compromise the vascular supply, such as diabetes, peripheral vascular disease and coronary artery disease, have been found in a high proportion of cases. ${ }^{2}$ Our patient had all of these comorbidities. Although she had no apparent predisposing eye or nasal wounds, unvisualized bleeding around the nasogastric tube and halitosis from underlying pneumonia may have contributed to the infestation.

Larvae in the Calliphoridae family can invade local tissues with minimal damage to deeper structures. However, numerous complications may occur with larvae of certain species, including erosion of bones and teeth, cellulitis, bacteremia and death., ${ }^{3,4}$ Treatment involves manual removal of the larvae and thorough irrigation of the affected tissues with saline or a dilute antimicrobial solution (e.g., hydrogen peroxide). Systemic antiparasitics are generally not required.

\section{Tom A. Szakacs MD}

Paul MacPherson MD PhD

Division of Infectious Diseases

University of Ottawa

The Ottawa Hospital
Bradley J. Sinclair PhD

Bruce D. Gill PhD

Entomology

Ontario Plant Laboratories

Anne E. McCarthy MD

Division of Infectious Diseases

University of Ottawa

The Ottawa Hospital

Ottawa, Ont.

This article has been peer reviewed.

Competing interests: None declared.

\section{REFERENCES}

I. Greenberg B. Two cases of human myiasis caused by Phaenicia sericata (Diptera: Calliphoridae) in Chicago area hospitals. J Med Entomol I984;21:615.

2. Sherman RA. Wound myiasis in urban and suburban United States. Arch Intern Med 2004;I60:2004-I4.

3. Chan JCM, Lee JSW, Dai DLK, et al. Unusual cases of human myiasis due to Old World screwworm fly acquired indoors in Hong Kong. Trans R Soc Trop Med Hyg 2005;99:914-8.

4. Josephson RL, Krajden S. An unusual nosocomial infection: nasotracheal myiasis. J Otolaryngol I993;22:46-7.
Every year, we distribute more than

1.5 million copies of CMAJ to Canadian physicians and health professionals around the world.

\section{CMAJ}

for the best of Canadian medicine

Orders and information:

CMA Member Service Centre

tel $888855-2555$ or

$613731-8610 \times 2307$

fax $613236-8864$

cmamsc@cma.ca
Chaque année, nous distribuons de par le monde plus de 1,5 million d'exemplaires du JAMC aux médecins et aux professionnels de la santé.

\section{Le JAMC}

tout simplement la crème de la médecine canadienne

Abonnements et demandes de renseignements :

Centre des services aux membres de l'AMC tél 888 855-2555 ou

$613731-8610 \times 2307$

fax $613236-8864$

cmamsc@cma.ca

\section{CMAJ·JAMC}

